\title{
SOURCES OF MYCORRHIZAL INFECTION OF SHOREA ACUMINATA SEEDLINGS UNDER LABORATORY CONDITIONS*)
}

\author{
LEESU SEE \\ Forest Research Institute of Malaysia \\ Kepong \\ 52109 Kuala Lumpur \\ Malaysia
}

\begin{abstract}
Uninoculated dipterocarp seedlings raised in normal field soil in nurseries were always found to have mycorrhizas after a few months. This study set out to determine whether dipterocarp seedlings could continue to grow and develop in the absence of mycorrhizas and also to determine possible sources of mycorrhizal infection of dipterocarp seedlings raised under laboratory conditions using Shorea acuminata as a typical example. Seedlings were planted in capped or uncapped perspex boxes containing sterile or non-sterile field soil and watered daily with sterile water or tap water. Seedling growth and development of mycorrhizas were monitored at monthly intervals for up to seven months. Seedlings grown in sterile soil remained uninfected after seven months while infection was found in some of the seedlings grown in normal soil regardless of whether they had been watered with tap water or sterile water. This showed that field soil (i.e. under grass) far from the forest contained suitable inoculum for forest tree seedlings. Tap water and the air were not important sources of infection. However, mycorrhizal infection was very uneven indicating that the inoculum was probably very unevenly distributed in the soil or that the inoculum density was rather low. Seedlings grown in sterile soil showed better growth than those grown in normal soil and infection of roots by parasitic fungi in the latter was also observed.
\end{abstract}

Key words: Mycorrhizas/Plant pathology/lnfections/Shorea acuminata/Seedlings.

\section{INTRODUCTION}

Enrichment planting is often conducted in logged forests in Malaysia to ensure adequate stocking of dipterocarps for future rotations. For this purpose, dipterocarp seedlings mostly of Shorea species are raised in nurseries whenever seed is available. Shorea species, especially of the red meranti group are important for their valuable hardwood timber. Under normal practice, freshly collected seeds with their wings removed are sown into boxes or beds containing washed sand or a soil/sand mixture. The seeds germinate very quickly, usually after five to seven days, and at the age of one month are transplanted into polybags containing an unsterilised mixture of

\footnotetext{
*)Paper presented at the Second Asian Conference on Mycorrhizae, ACOM 91, March 12-17, 1991. Chiang Mai, Thailand.
} 
sand and top soil. The seedlings can be maintained in the nurseries without any fertilizer application for quite some time before outplanting without any visible symptoms of poor health. Plants of over one year-old have been observed to do well in the nursery. No mycorrhizal inoculum is added but the roots of the seedlings are usually found to be ectomycorrhizal by about three months (unpubl. data; Lee 1988). An account of the mycorrhizal association of the Dipterocarpaceae is given by Lee (1990).

Smits et al. (1988) reported that dipterocarp seedlings could not be successfully raised in the nursery in East Kalimantan and that seedlings transplanted into secondary forest usually died. They stated that dipterocarps are obligately ectomycorrhizal and are thus unable to survive unless associated with their specific fungal partner(s) (Smits 1983, 1985; Noor and Smits et al. 1987). Moreover, Smits et al. (1988) advocated various methods of inoculation of dipterocarp seedlings to ensure survival and successful establishment in the nursery and forest.

This study was conducted to determine whether dipterocarp seedlings could continue to survive and develop in the absence of mycorrhizas and also to determine possible sources of mycorrhizal infection of seedlings raised under laboratory conditions similar to those found in the nursery.

\section{MATERIALS AND METHODS}

\section{Experimental design}

The experimental design was a randomised 2.2.2 factorial: \pm steamed soil, \pm cap, \pm watering with sterile tap water. Each treatment consisted of five replicates.

\section{Plant material}

Shorea acuminata Dyer seeds were obtained from trees growing in Field 3 in the compound of the Forest Research Institute of Malaysia (FRIM) and germinated in boxes containing washed sand. S. acuminata is common in mixed dipterocarp forest and yields timber classed in the light red meranti group.

\section{Soil mixture and planting}

Top soil was collected from under grass at the farm in Universiti Pertanian Malaysia and sieved to remove stones, roots and other organic debris before mixing with vermiculite in the ratio of 7:3. One portion of the soil mixture was stored for later use while the other portion was steamed in a soil steamer for one hour 
on two consecutive days. The steamed and cooled soil mixture was then incubated in a tightly closed black plastic bag in the greenhouse for two weeks before further use.

Perspex boxes consisting of two sheets of clear perspex measuring $30 \mathrm{~cm}$ x $20 \mathrm{~cm}$ separated by a $1.5 \mathrm{~cm}$ polystyrene spacer and bound together with "cling film" were used as pots for the seedlings. A one month-old seedling was transplanted into each box with its roots in contact with one sheet of perspex. The boxes were then wrapped in black plastic and placed in plastic basins in the laboratory under a bank of fluorescent tubes emitting cool white light at an intensity of about 2000 lux. The daily temperature ranged from a maximum of $32^{\circ} \mathrm{C}$ to a minimum of $23^{\circ} \mathrm{C}$. Caps for the boxes were made from aluminium foil with a perforation to allow the seedling to emerge. Caps were also fitted with a glass tube to facilitate watering. The plants were watered daily with either sterile or normal tap water.

\section{Measurement and analysis}

At fortnightly intervals seedling height was measured and the roots inspected for formation of ectomycorrhizas. When present mycorrhizas were clearly visible through the clear perspex under the stereomicroscope. The experiment was terminated after seven months.

Relative growth rates were used to compare the performance of the seedlings under the various treatments.

\section{RESULTS AND DISCUSSION}

All $S$. acuminata seedlings grown in steamed soil remained non-mycorrhizal but healthy after seven months. Leaving the boxes uncapped did not produce any infection in the seedlings; neither did watering with normal tap water. It appeared that tap water and the air were not important sources of infection as had earlier been postulated and that steaming the soil mixture was effective in preventing infection. The results indicated that dipterocarp seedlings could easily survive and develop normally for up to seven months in the absence of ectomycorrhizas and fertilizer application.

Ectomycorrhizal infection of seedlings grown in normal soil appeared to be a random process. At least one seedling in each treatment ( \pm cap, \pm sterile tap water) was infected after seven months (Table 1). Since the soil mixture was the only common factor in all the treatments, and steaming the soil eliminated ecto-mycorrhizal infection, it appeared that the soil was the main source of infection. 
The random pattern of infection and the low infection rate was probably an indication of the random natural distribution and low density of the mycorrhizal inoculum in the field soil. It also appeared that soil under grass located several kilometers from the forest contained suitable dipterocarp mycorrhizal inoculum. It had previously been assumed, and in fact Smits and co-workers (1988) reported, that such areas would not contain any suitable dipterocarp inoculum in the absence of dipterocarp host trees.

Earliest infection occurred at week 10 while infection was last observed to occur at week 17 (Table 1). Two main types of ectomycorrhizas were observed. These mycorrhizas have also been commonly observed on roots of nursery seedlings (un-publ. data). Uninfected seedlings continued to grow normally but were generally smaller than the infected seedlings as reflected in the relative growth rates shown in Figure 1. It appeared that ectomycorrhizas enhanced the growth of infected seedlings, the effect being more dramatic the earlier the infection.

Table 1. Ectomycorrhizal infection of $S$. acuminata seedlings grown in normal soil under various treatments

\begin{tabular}{lcc}
\hline \hline Treatment & $\begin{array}{c}\text { Number of seedlings } \\
\text { infected }\end{array}$ & $\begin{array}{c}\text { Infected at } \\
\text { week }\end{array}$ \\
\hline Tap water, uncapped & 1 & 10 \\
& $1(2 / 5)$ & 17 \\
Tap water, capped & $1 \mathrm{~d} / 5)$ & 11 \\
Sterile tap water, capped & $1(1 / 5)$ & 17 \\
Sterile tap water, uncapped & 1 & 13 \\
& $1(2 / 5)$ & 17 \\
\hline
\end{tabular}

* Figures in parentheses indicate the total number of infected seedlings in each treatment at the end of 7 months.

Roots of a number of seedlings grown in normal soil were attacked by root pathogenic fungi such as Cylindrocladium sp. resulting in death of roots, the cessation of growth and yellowing of three seedlings after 10 weeks and the death of one seedling after 17 weeks. Cylindrocladium spp. are relatively common in local soils and have been observed to be associated with death of dipterocarp seedlings in the natural forest (unpubl. data). Attack by such root pathogenic fungi could have caused the death of the dipterocarp seedlings reported by Smits and co-workers (1988) in Indonesia.

In comparison, all seedlings grown in steamed soil were healthy with normal green foliage until the end of the experiment and had much more extensive but 


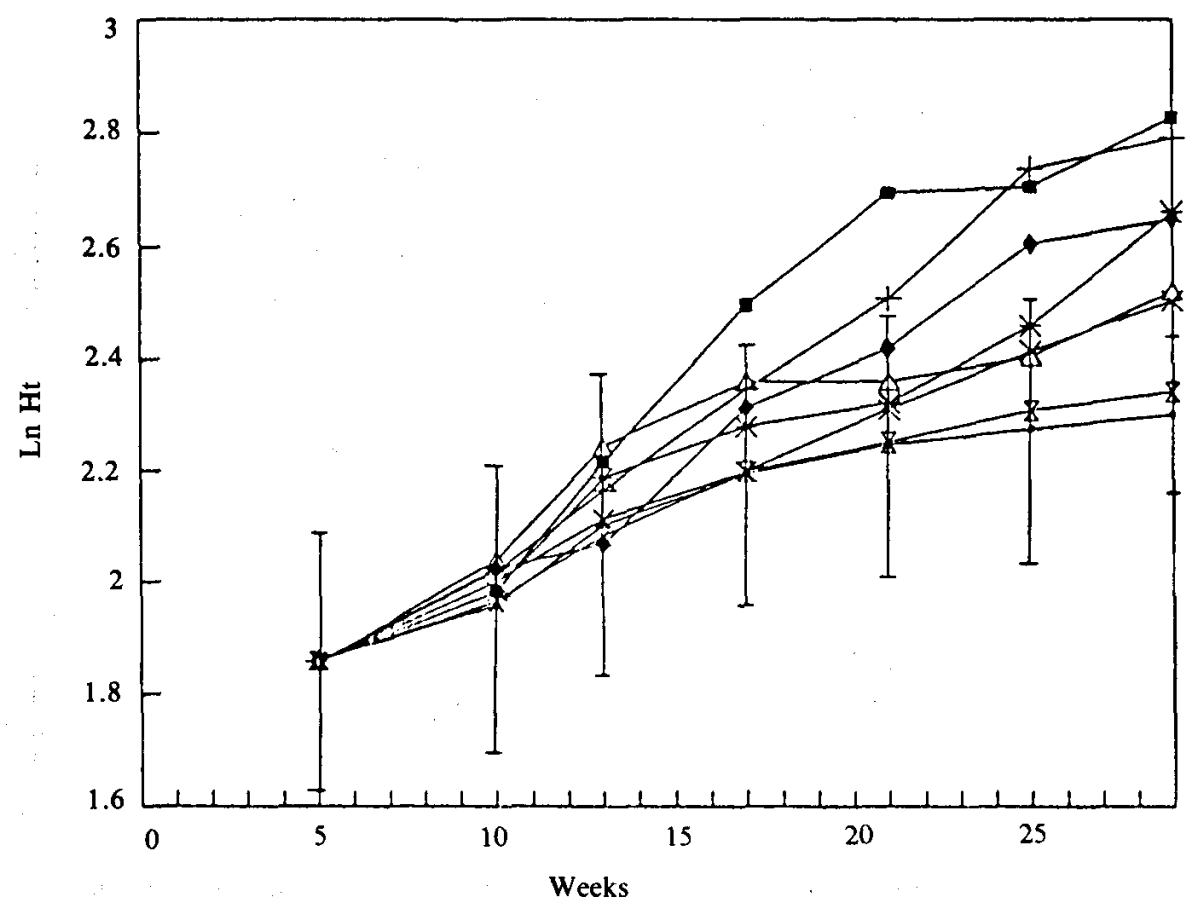

Figure 1. Relative growth rates of Shorea acuminata under different treatments in normal unsterilised soil: -Itap water, capped; * $\square$ tap water, uncapped; $x$ sterile water, capped; $\ \nabla$ sterile water, uncapped; Mean ( \pm s.d.) for uninfected seedlings.

normal uninfected root systems than seedlings grown in normal soil. Steaming the soil before planting probably killed all potentially pathogenic organisms resulting in better seedling survival. The mean relative growth rates of seedlings grown in unsterilised or steamed soil were not significantly different ( $\mathrm{p} \leq 0.05)$ after 29 weeks (Fig. 2). Although the use of steamed soil for planting may results in higher survival rates and generally produce healthier plants, the economics of the practice must be given serious consideration before it can be adopted on a routine basis.

Based on the results of this study it would appear that the potting medium used for planting dipterocarp seedlings in the nursery is the main source of ecto-mycorrhizal inoculum and that earliest formation of ectomycorrhizas in the field normally takes a period of about 10 to 12 weeks. The inoculum found in field soil was also compatible with the seedlings and appeared to promote better growth. Therefore, there appears to be no absolute necessity to inoculate dipterocarp seedlings in the nursery unless local conditions are such that absolutely no suitable inoculum 


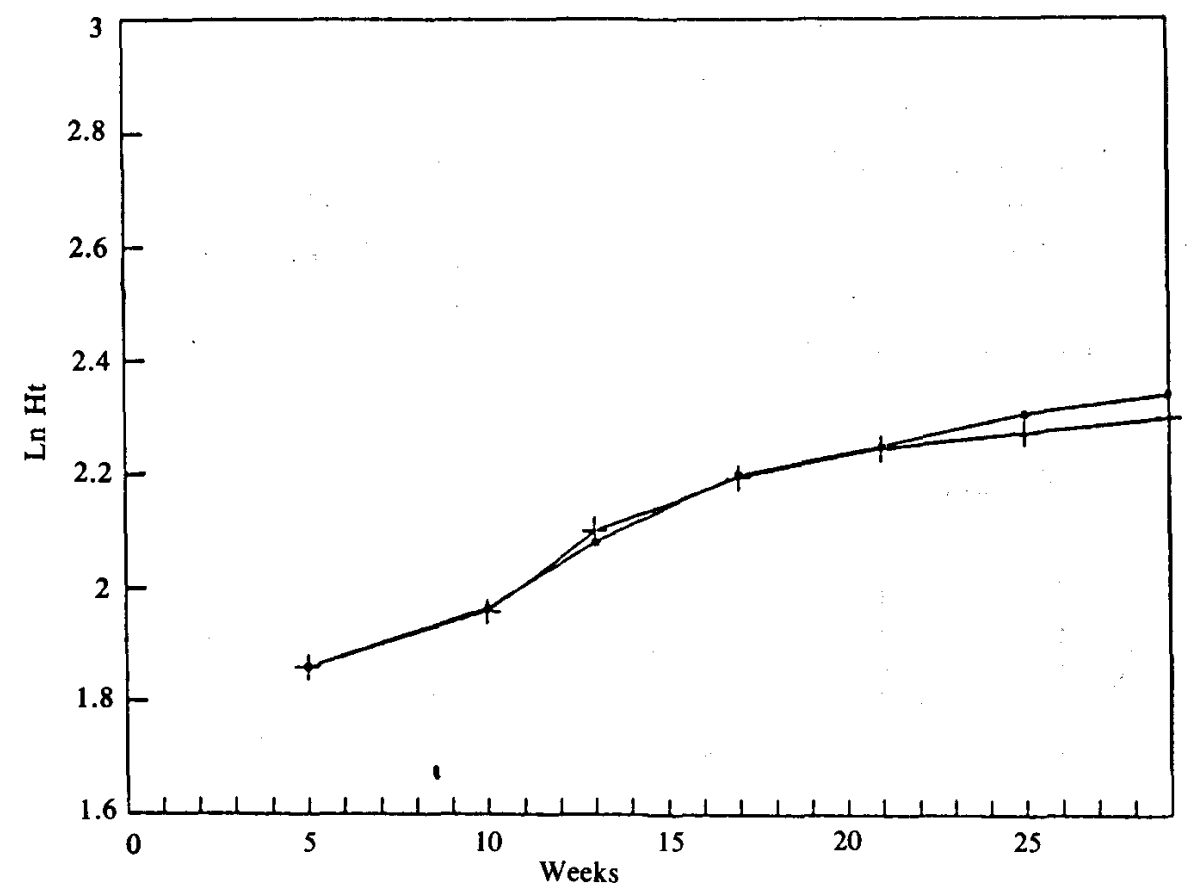

Figure 2. Mean relative growth rates of Shorea acuminata in steamed soil $(\bullet)$ and in normal unsterilised soil $(+)$.

is present. This would be highly unlikely since the results of this study show that soil located several kilometers from forest areas without dipterocarp host trees could still initiate ectomycorrhizal infection producing enhanced growth in infected plants. It should further be pointed out that nursery-raised dipterocarp seedlings offfopea and Shorea spp. have been successfully planted, growing into normal trees in parks and urban areas. This further suggests that survival and normal development of dipterocarp seedlings can be achieved without inoculation with specific fungi.

However, this does not mean that mycorrhizal inoculation of dipterocarps should be ignored as it has been shown that mycorrhizal infection definitely enhances the growth of seedlings. Efforts should be made to find the most suitable mycorrhizal fungi and methods of inoculation for the economic production of dipterocarp seedlings suitable for planting in logged-over forests and other cleared areas to ensure the best chances for their survival and growth. 


\section{ACKNOWLEDGEMENTS}

I would like to thank SEAMEO BIOTROP for sponsoring my attendance at this conference, the International Foundation for Science for a grant that made this study possible, the Dean of the Faculty of Forestry, Universiti Pertanian Malaysia for use of facilities during my tenure there, and the Director-General of the Forest Research Institute of Malaysia (FRIM) for permission to present this paper.

\section{REFERENCES}

LEE, S.S. 1988. Do mycorrhizas play a role in the growth and development of Parashorea densiflora Sloot \& Sym.? In: M. Mohinder Singh (ed.). Agricultural and Biological Research Priorities in Asia. Proceedings of the IPS Symposium of SCIENCE ASIA '87. 14-17 October, Kuala Lumpur, p. 167-171.

LEE, S.S. 1990. The mycorrhizal association of the Dipterocarpaceae in the tropical rain forest of Malaysia. AMBIO 19(8): 383-385.

NOOR, M. and W.T.M. SMITS. 1987. Pengaruh intensitas cahaya dan suhu tanah terhadap ektomikoriza dan pertumbuhan anakan Shorea polyandra. In: Komar Soemarna, Harun Alrasyid, Ishemat Surianegara dan Achdiat (eds.). Presiding Simposium Hasil Penelitian Silvikultur Dipterocarpaceae, 24 November 1987. Jakarta, Indonesia, p. 11-30.

SMITS, W.T.M. 1983. Dipterocarps and mycorrhiza: An ecological adaptation and a factor in forest regeneration. Flora Malesiana Bull. 36: 3926-3937.

SMITS, W.T.M. 1985. Specificity of dipterocarp mycorrhiza. In: R. Molina (ed.). Proc. 6th NACOM. 25-29 June, 1984. Bend, USA.

SMITS, W.T.M., D. LEPPE and M. NOOR. 1988. Metode inokulasi untuk persemaian Dipterocarpaceae. Edisi Khusus No. 5, Balai Penelitian Kehutanan Samarinda. 